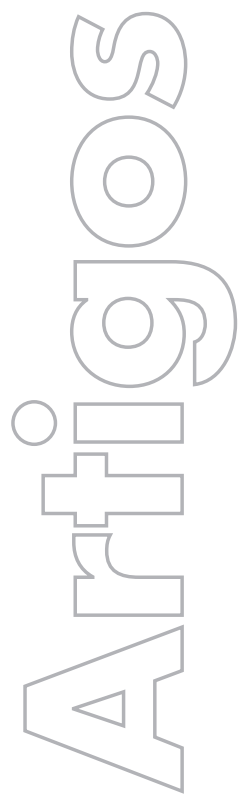

revista

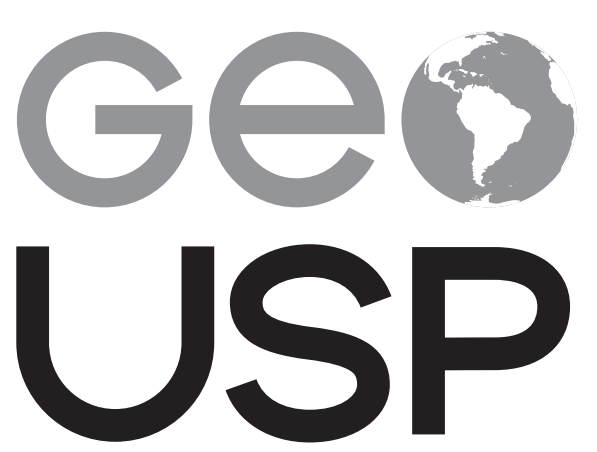

espaço e tempo

Volume $22 \cdot n^{\circ} 3$ (2018)

ISSN 2179-0892
Ouro para fora, lixo para dentro: as inserções de Gana

na divisão internacional do trabalho contemporânea e a recomodização da economia

Kauê Lopes dos Santos

USP

p. 607-622

Como citar este artigo:

SANTOS, K. L. Ouro para fora, lixo para dentro: as inserções de Gana na divisão internacional do trabalho contemporânea e a recommodização da economia. Geousp - Espaço e Tempo (Online), v. 22, n. 3, p. 607-622, dez. 2018. ISSN 2179-0892.

Disponível em: <https://www.revistas.usp.br/geousp/article/view/137274>. doi: http://dx.doi.org/10.11606/issn.21790892.geousp.2018.137274.

\section{(C) $(1) \Theta$}

Este artigo está licenciado sob a Creative Commons Attribution 4.0 License. 


\title{
Ouro para fora, lixo para dentro: as inserções de Gana na divisão internacional do trabalho contemporânea e a recomodização da economia ${ }^{1 *}$
}

\section{Resumo}

A formação socioespacial ganense tem uma rica variedade de recursos minerais que atualmente são explorados e exportados por grandes corporações estrangeiras. Ao mesmo tempo, devido à precarização da indústria nacional ao longo das últimas décadas, Gana tornou-se altamente dependente da importação de bens manufaturados e, mais especificamente, de bens manufaturados de segunda mão, em especial, de eletroeletrônicos importados da Europa e da América do Norte. Aproximadamente $70 \%$ desses bens não podem ser usados em suas funções originais, tornando-se lixo eletroeletrônico que, por sua vez, induz o surgimento de uma série de atividades econômicas em Accra que dão origem ao processo de recommodização da economia, responsável por tornar mais complexa a inserção de Gana na divisão internacional do trabalho contemporânea.

Palavras-chave: Ouro. Lixo eletroeletrônico. Gana. Divisão internacional do trabalho. Recommodização.

\section{Gold out, waste in: the inserts of Ghana in the contemporary international labor division and the economy recommodization}

\begin{abstract}
Ghana's socio-spatial formation has a rich variety of mineral resources that are currently exploited and exported by large foreign corporations. At the same time, due to the precariousness of national industries over the last few decades, Ghana has become highly dependent on imported manufactured goods and, more specifically, on second-hand manufactured goods, especially electronics imported
\end{abstract}

* O autor é pesquisador de pós-doutorado do IEE-USP, financiado pela Fapesp. Processo n. 2017/22067-0. 
from Europe and North America. Approximately 70\% of these goods can not be used in their original functions, becoming electronic waste that in turn stimulates the emergence of a series of economic activities in Accra that give rise to the process of recommodization of the economy, a process that is responsible for making more complex the insertions of Ghana in the contemporary international labor division.

Keywords: Gold. E-waste. Ghana. International labor division. Recommodization.

\section{Introdução}

O presente artigo objetiva estabelecer uma análise acerca das inserções de Gana ${ }^{2}$ na divisão internacional do trabalho (DIT) contemporânea. Para tanto, será feita uma apresentação das recentes dinâmicas do comércio exterior do país e, em seguida, uma caracterização aprofundada das atividades que são responsáveis por aquilo que será aqui denominado recommodização da economia, que é o conjunto de atividades associadas à importação e ao processamento de lixo eletroeletrônico no país.

Assim, Gana será analisada por meio do conceito de formação socioespacial. Desenvolvido na década de 1970 por Milton Santos, esse conceito é considerado uma de suas principais contribuições à ciência geográfica (Mamigonian, 1996). Essa contribuição é notadamente uma derivação do conceito marxista de formação econômica social, que visa compreender as especificidades do desenvolvimento dos modos de produção pelo mundo, permitindo entender melhor a diferente evolução das sociedades e de sua economia ao longo do tempo (Santos, M., 1977).

$\mathrm{Na}$ época em que elaborou o conceito de formação socioespacial, Milton Santos argumentou que o espaço - instância geralmente posta em segundo plano nas análises dos economistas, sociólogos e cientistas políticos - também tinha um papel central no desenvolvimento das especificidades nacionais dos modos de produção anunciado por Marx. Justamente por esse motivo, o geógrafo incorporou a dimensão espacial em sua conceituação, assegurando que:

As diferenças entre os lugares são o resultado do arranjo espacial dos modos de produção particulares. $\bigcirc$ "valor" de cada local depende de níveis qualitativos e quantitativos dos modos de produção e da maneira como eles se combinam (Santos, M., 1977, p. 87).

A importância da formação socioespacial também reside no fato de que o conceito é capaz de constranger análises generalistas feitas na escala da região ou do continente, que são muito comuns em estudos acadêmicos sobre temas que se desenvolvem na África. Evi-

2 Gana, antiga Costa do Ouro, alcançou sua independência dos britânicos em 1957, tornando-se uma república que hoje funciona como uma democracia constitucional. Fica na África Ocidental, tendo uma extensão territorial de 238,533 km2 e uma população de aproximadamente 25 milhões de habitantes. $\bigcirc$ país é banhado pelo Oceano Atlântico em sua porção sul, faz fronteira com a Costa do Marfim a oeste, Burkina Fasso a norte e Togo a leste. No que tange a seus aspectos físico-naturais, o relevo do território é majoritariamente composto por planícies e baixos planaltos (sobretudo na porção centro-sul), o clima é predominantemente tropical, sendo mais seco ao norte. Por fim, a vegetação é caracterizada pela ocorrência de savanas (ao norte), florestas tropicais (ao sul) e vegetação rasteira (no litoral). 
dentemente, isso não significa, por exemplo, que o modo de produção em Gana não tenha se desenvolvido de maneira semelhante ao de outros países, mas significa entender como essas semelhanças foram construídas ao longo de determinado processo histórico, o mesmo que instaurou as diferenças e as especificidades do modo de produção na escala nacional.

Assim, com base no conceito de formação socioespacial, as etapas metodológicas que orientaram o estudo e a apresentação dos argumentos contidos neste artigo se pautaram na sistematização de fontes secundárias - livros, artigos acadêmicos, artigos jornalísticos, anuários estatísticos, leis e decretos do governo ganense - e primárias. Os trabalhos de campo para Gana ocorreram em 2013 e em 2016, com entrevistas abertas e semiestruturadas com diversos tipos de instituições que atuam na economia do país como ministérios, associações de empresas e empresas públicas e privadas. Ao mesmo tempo, registraram-se as paisagens urbanas de Accra em forma de descrição densa (Geertz, 1963) e de fotografias. É importante mencionar aqui a dificuldade de entrevistar trabalhadores empregados nas atividades que operam a recommodização da economia, uma vez que a maior parte deles fala apenas os idiomas locais ou não estava disposta a conceder entrevistas em função do status de ilegalidade de seu emprego.

\section{Aspectos gerais da dinâmica de exportação e importação da formação socioespacial de Gana no início do século XXI}

Semelhante ao ocorrido em outras formações socioespaciais africanas ao sul do Saara, Gana consolidou historicamente seu papel na DIT como produtora de commodities, especialmente do ouro, ${ }^{3}$ que em 2016 representou 42\% do valor obtido com as exportações nacionais a partir de um total de US\$10,5 bilhões. No mesmo ano, outras commodities, como o cacau e o petróleo, tiveram uma participação menos expressiva na economia - 18 e $9 \%$, respectivamente -, apesar de também figurarem como importantes produtos na pauta de exportação nacional (Observatory of Economic Complexity, [s.d.]).

As condições geológicas da formação socioespacial ganense explicam não apenas a disponibilidade das reservas de ouro, mas também de outros minerais menos explorados, como a bauxita e o manganês. A maior parte desses recursos estão nas porções sul, sudoeste e oeste do país, que são áreas de ocorrência predominante de rochas paleo-proterozoicas subdivididas em três grupos: Tarkwa (quartzito, filito, grits e conglomerados), Birimian Superior (lavas metamorfoseadas e rochas piroclásticas) e Birimian Inferior (filito, xistos) (Schluter, 2006).

No que tange à apropriação desses recursos ao longo da história do país, deve-se considerar que, a partir da independência do jugo colonial britânico em 1957 - e, em especial, durante os governos de Kwame Nkrumah (1957-1966) e Ignatius Acheampong (1972-1978) -, Gana passou por um período de estatização da economia que durou até a década de 1980. Ao longo

3 Explorado desde o século XII pelos Estados das porções meridionais da África Ocidental, o ouro era vendido na Europa e no Oriente Médio através das rotas transaarianas (Davidson, 1985). A partir do século XVI, a exploração do mineral foi relegada em função da consolidação do tráfico atlântico, cuja prioridade era capturar e escravizar homens e mulheres de origem africana para trabalho compulsório nas Américas. Essa situação só foi alterada com o declínio do tráfico negreiro, em fins do século XVIII, e pela colonização europeia na África, em fins do XIX, quando os recursos minerais do continente passam a ser explorados por empresas de capital europeu. No caso da Costa do Ouro (nome que Gana recebeu quando estava sobre o controle do Reino Unido), o ouro passou a ser explorado pela empresa britânica Ashanti Goldfields Corporation (Boahen, 1975). 
desses anos, implementou-se uma série de políticas industriais (visando substituir importações) e agrícolas (visando a segurança alimentar), que foram acompanhadas por maciços investimentos nacionais, estadunidenses e soviéticos em infraestruturas de transporte e energia. No setor da mineração, e mais especificamente da mineração aurífera, houve a estatização da Ashanti Goldfields Corporation e a criação da State Gold Mining Corporation (Anin, 1989). Não de outro modo, essas políticas de cunho nacional-desenvolvimentista buscaram subverter a lógica econômica herdada do período colonial, na qual cabia à Costa do Ouro exportar bens minerais, vegetais e agropecuários e importar bens industrializados (Santos, K., 2017).

Porém, na década de 1980 e início da de 1990, em função do agravamento da recessão econômica internacional, começou um período que perdura até a década de 2010 e que se caracteriza pela adequação das políticas econômicas de diversas formações socioespaciais africanas em direção à ideologia neoliberal. Com o objetivo de obter suporte financeiro de instituições multilaterais - como o Fundo Monetário Internacional (FMI) e o Banco Mundial - muitos países do continente lançaram seus Planos de Ajuste Estrutural (PAE), que anunciavam a abertura de seus mercados ao capital internacional e a privatização de empresas estatais, além de uma série de medidas relativas a ajustes fiscais e monetários. Soma-se a isso o fato de que, quando disponibilizados, os investimentos externos priorizavam os setores econômicos associados à produção de commodities (Rothchild, 1991; Hutchful, 2002).

Em Gana, sob o governo de J. J. Rawlings (1979-2001), o conjunto de políticas neoliberais adotado foi responsável pela privatização de grande parte das empresas estatais de diferentes setores, inclusive da mineração. Essas políticas, que se atrelavam à abertura do mercado nacional ao capital externo, também ajudaram a desenvolver o capital nacional privado em atividades acessórias à exploração mineral (Rothchild, 1991; Rimmer, 1992).

Desse modo, enquanto grandes corporações sul-africanas (Anglogold Ashanti e Gold Fields), canadenses (Golden Star e Chirano Gold Mines), australianas (Adamus Resources e Perseus Mining Limited) e estadunidenses (Newmont Mining Corporation) passaram a explorar a maior parte do ouro ganense, o capital nacional privado tornou-se presente em empresas de consultoria, logística e manutenção de maquinários. $\bigcirc$ Estado ainda tem um papel muito importante nesse contexto, estabelecendo as leis do setor, o sistema de tributação das corporações que nele atuam e a organização das infraestruturas de escoamento, que por vezes conta com a presença de empresas estrangeiras no formato das chamadas joint ventures (Santos, K., 2017).

O se pode observar na atualidade é que a ascensão das políticas neoliberais em Gana fez com que se estabelecesse um padrão de comércio exterior semelhante ao do período colonial, imputando às forças produtivas da formação socioespacial uma organização econômica canalizada para a produção de commodities, ao passo em que aumentou a importação de bens industrializados. Tomando como referência o ano de 2016, as exportações registraram US\$ 10,5 bilhões, enquanto as importações alcançaram US $\$ 11$ bilhões, criando um deficit de meio bilhão (Observatory of Economic Complexity, [s.d.]).

No âmbito das importações - que são igualmente importantes na análise aqui pretendida - em 2016, Gana comprou uma ampla variedade de produtos de outros países, de modo que os principais deles estão listados a seguir (Observatory of Economic Complexity, [s.d.]): 
- 39\% de máquinas, maquinários e peças de manutenção: telefones, computadores, aparelhos de vídeo cassete/DVD, luz portátil, máquinas de escavação, veículos de construção de grande porte, máquinas de processamento de rochas, automóveis, caminhões, motos, tratores, navios e peças de automóveis, fios isolados, válvulas etc.,

- $16,7 \%$ de produtos de origem mineral e metálica com diferentes níveis de processamento: petróleo bruto e refinado, cimento, ferro laminado plano revestido, estruturas de ferro, barras de aço etc.,

- 13,1\% de produtos químicos e petroquímicos: medicamentos, agrotóxicos, pneus, tampas de plástico etc.

O Serviço Estatístico de Gana (Ghana Statistical Service, GSS), identifica as principais origens das mercadorias importadas:

As importações de Gana são principalmente suprimentos industriais, bens de capital, bens de consumo, petróleo e alimentos, de modo que China, EUA, Bélgica, Reino Unido e França são os principais fornecedores (Ghana Statistical Service, 2015, p. 24, tradução nossa).

Esse padrão demonstra as demandas da economia nacional que o próprio território não é capaz de suprir, em especial no âmbito da indústria nacional. Contudo, esse padrão - que é geral e comum à maior parte dos países do sul - ainda não é suficiente para qualificar mais profundamente o papel de Gana na DIT contemporânea: a partir de uma análise pormenorizada das importações ganenses recentes, revela-se que o país tem desempenhado um papel muito mais complexo que o de simples exportador de commodities e importador de bens industrializados.

Dentro do conjunto de produtos industrializados importados por Gana figuram os objetos de segunda mão, caracterizados por já terem sido utilizados e descartados por consumidores de outras localidades, sobretudo de países do norte. Integram essa lista: veículos, maquinários e, principalmente, bens eletroeletrônicos que, em sua maior parte, chegam ao porto de Tema - cidade portuária conurbada a Accra - em estágios irreversíveis de deterioração, sendo considerados, portanto, lixo eletroeletrônico, também denominado resíduo de equipamento eletroeletrônico (Reee) ou e-waste. Enquanto o ouro e outras commodities saem do território como matéria-prima rumo às industrias da Europa, Ásia e América do Norte, o lixo entra em diversas formações socioespaciais africanas e viabiliza o desenvolvimento de um série de atividades responsáveis pelo processo que será aqui denominado recommodização da economia.

\section{Importação de lixo eletroeletrônico}

Nos últimos anos, o lixo eletroeletrônico viabilizou o desenvolvimento de uma série atividades econômicas em Gana, sobretudo no seu espaço urbano. Em linhas gerais, essas atividades envolvem o reparo desse resíduo ou a extração dos minérios nele presentes: enquanto o primeiro conserta objetos em diferentes níveis de deterioração para vendê-los no mercado interno, o último retira os minérios dos objetos completamente danificados para vendê-los no mercado externo. Essas atividades ocorrem fundamentalmente na capital Accra e se caracterizam pela precariedade das condições de trabalho, no cenário de informalidade que foi intensificado após o ajuste do país à política neoliberal, desde a década de 1980. 
A massa desses produtos descartados que chega em Gana origina-se principalmente nos países da Europa Ocidental, nos EUA e no Canadá, correspondendo a mais uma externalidade criada pelo grande capital industrial, que - ao estimular a obsolescência programada de seus produtos e a publicidade para o consumo dos mesmos - mostra-se descomprometida com a produção do lixo. ${ }^{4}$

Grande parte do lixo eletroeletrônico produzido no mundo não é reciclado ou tratado em sua área de produção, o que aponta necessariamente para sua circulação, distribuição e comercialização. Desde a década de 1990, diversos teóricos da chamada globalização anunciam a existência de um processo sem precedentes de aceleração e internacionalização de diferentes tipos de fluxos, dando ênfase às mercadorias, aos serviços, ao capital, à informação e às pessoas. Contudo, na maior parte dessas análises, o fluxo de lixo ganhou pouca ou nenhuma atenção.

A circulação e distribuição de lixo também deflagra o aprofundamento da divisão internacional do trabalho na contemporaneidade, sendo mais uma manifestação categórica da globalização como perversidade, apresentada e criticada por Milton Santos (2000). Nesse processo, o fluxo de lixo parte dos países do norte em direção às formações socioespaciais da África e da Ásia, reforçando a já explícita assimetria que compõe a estrutura da DIT.

Os esforços internacionais para regular o fluxo internacional de lixo foram apresentados numa série de fóruns desde o fim da década de 1980, tendo o mais importante deles sido a Convenção de Basileia, realizada na Suíça, em 1989. Essa convenção criou o único tratado global que objetiva controlar o movimento internacional de resíduos perigosos, incluindo aí o lixo eletroeletrônico. Outras convenções também tiveram como objetivo a redução e o controle do fluxo de lixo entre países, como a Convenção de Bamako (Mali, 1991), a Convenção de Roterdã (Holanda, 1998) e a Convenção de Estocolmo (Suécia, 2001) (United Nations Environmental Programme, 2015).

É muito complexo mensurar o fluxo desse lixo, em razão das várias maneiras com que se pode classificar um objeto descartado. Estima-se que $70 \%$ da massa de produtos eletroeletrônicos que chega a Gana esteja em estado total de deterioração (Grant, 2016) e, nos últimos anos, esse fluxo tem sido reportado principalmente por agências de pesquisa da $\mathrm{ONU}$, de $\mathrm{ONG}$ e de ambientalistas independentes. A especificidade do lixo eletroeletrônico reside no fato de que ele pode ser extremamente nocivo à saúde humana e ao ambiente se não for adequadamente armazenado e processado por meio de custosas infraestruturas de reciclagem.

Segundo dados da Polícia Internacional (Interpol), cerca de 90\% do e-waste mundial é comercializado ilegalmente, depositado em lixões e processado informalmente. Soma-se aí o fato de que, no ano de 2014, 42 milhões de toneladas de lixo e-waste foram geradas, o equivalente a US\$ 50 bilhões (United Nations Environmental Programme, 2015).

$\mathrm{Na}$ atualidade, uma quantidade expressiva desse lixo tem se acumulado nas periferias de cidades portuárias não apenas de Gana, mas também do Senegal, da Libéria, da Costa do Marfim, de Togo, da Nigéria, do Congo, do Egito, do Paquistão, da Índia, do Vietnã, de Bangladesh e da China, entre outros países do sul (United Nations Environmental Programme, 2015).

4 Nesse contexto, a produção de lixo tem alcançado proporções sem precedentes: nas cidades dos países desenvolvidos, ela aumentou 23\%, saltando de 530 para 650 milhões de toneladas entre 1990 e 2006 (Moore, 2011). 
No entanto, Gana tornou-se uma das principais destinações desse fluxo em função do estabelecimento de uma política nacional alfandegária que reduziu a zero as taxas de importação para produtos eletrônicos, incluindo aqueles classificados como de segunda mão. A justificativa oficial dessa política foi a de que ela viabilizaria o acesso da população pobre do país - 44\% dos ganenses tem poder aquisitivo de inferior a l dólar por dia - ao chamado mundo digital, por meio do consumo das tecnologias de comunicação e informação (information communication technologies, ICT). Esse fluxo se intensificou em meados da década de 2000. De acordo com Grant e Oteng-Ababio (2012, p. 2, tradução nossa):

Em 2004, o governo de Gana implementou uma nova política para conectar o fosso digital, reduzindo o imposto de importação para zero em computadores usados e abrindo o caminho para o país tornar-se um ímã para navios com lixo eletroeletrônico. Um ambiente político nacional facilitador foi mantido [por exemplo, em 2009, a iniciativa "um laptop por criança" (Kotey, 2010), ${ }^{5}$ bem como o projeto de "um laptop por unidade familiar" (Reducing [...], 2009, p. 19)], ${ }^{6}$ com consequências inesperadas.

Assim, a despeito dos acordos internacionais que visam frear o fluxo transfronteiriço de lixo, a formação socioespacial ganense estabeleceu um acelerador para esse mesmo fluxo. É difícil mensurar a dimensão do volume de lixo eletroeletrônico que aporta em Gana, já que os contêineres que são dispostos no porto de Tema incluem tanto objetos completamente danificados (e inutilizáveis dentro de suas funções originais) quanto aqueles que, com diferentes níveis de uso, podem ser reparados e vendidos no mercado local, mesmo que tenham uma durabilidade curta e passem a integrar, num futuro próximo, o volume de resíduos do país. Atualmente, estima-se que cheguem mensalmente ao porto de Tema algo entre 300 e 600 contêineres do material - cada um com capacidade de 67,6 m³ (Oteng-Ababio, 2012; Grant, 2016).

Entre os objetos que integram esse tipo de lixo, podem-se destacar computadores (desktops e laptops), tablets, telefones celulares, aparelhos de telefone fixo, aparelhos de som, impressoras e máquinas copiadoras, monitores (LCD, LED e CTR), carregadores em geral, drives, estabilizadores, filtros de linha, fios e cabos eletrônicos, fontes, HD, hubs, roteadores, switches, mouses, teclados, placas eletrônicas e quadros elétricos de controle.

A importação de e-waste e as atividades relativas a seu processamento tornaram-se objeto de muitas reportagens investigativas nos últimos anos (The Guardian em 2014, Al Jazeera em 2015 e Carta Capital em 2015). Nessas reportagens, imagens de Agbogbloshie - o bairro de Accra onde fica um dos maiores depósitos de lixo eletroeletrônico do mundo - revelam uma paisagem urbana marcadamente precária em termos de infraestrutura, em que se acumulam resíduos de diferentes partes do mundo desenvolvido. Conhecido localmente como Sodoma e Gomorra, o bairro é o espaço onde diversos tipos de atividades econômicas se desenvolvem e operam o processo de recommodização da economia.

\footnotetext{
5 Kotey, L. A. Ghana, Education Minister: "One Laptop Per Child” Is Good But.... All Africa. Disponível em: http:// allafrica.com/ stories/201003100839.html. Acesso: 9 maio 2011.

6 Reducing poverty through IT. Ghanaian Times, 3 ago. 2009.
} 


\section{A recommodização da economia e a paisagem de Agbogbloshie}

A extração e o processamento dos recursos minerais advindos do lixo eletroeletrônico são precisamente as atividades que dão origem ao que aqui é denominado recommodização da economia. $\bigcirc$ fato de esses recursos serem obtidos por técnicas diferentes das empregadas na mineração tradicional impede que sejam analisados como uma commodity no sentido usual. A ideia de que existe uma reciclagem ou um reaproveitamento de determinado recurso mineral permite, a partir de um resíduo, pensar na produção de recommodities, e o prefixo re reitera essa noção. Além disso, assim que são processados, esses recursos chegam aos mercados internacionais com valores mais baixos que os seus correspondentes advindos da mineração tradicional, como veremos adiante.

Essa distinção entre commodity e recommodity é fundamental, visto que se trata de outro tipo de produto originado em outro tipo de atividade que, articulada à escala econômica internacional, acaba por deflagrar um novo modo de inserção da formação socioespacial ganense na DIT, no alvorecer do século XXI. A recommodização da economia é, portanto, um processo no qual um país também passa a exportar as recommodities obtidas no lixo, e não na natureza.

$\bigcirc$ processo de recommodização em Gana oferece ao mercado internacional recursos minerais por um preço mais baixo que o mercado tradicional de commodities. Ainda são poucas as análises das exportações de recommodities e de seus preços e consumidores no mercado internacional. Os estudos de Oteng-Ababio (2012), no entanto, revelam os preços favoráveis dessas mercadorias produzidas em Gana, em especial no caso do cobre, do brass (liga metálica feita de cobre e zinco), do zinco, do alumínio e do ferro (Tabela 1).

\section{Tabela 1 - Preço do metal em Agbogbloshie (Accra, Gana) e no mercado internacional - 2012}

\begin{tabular}{|l|l|l|}
\hline metal & $\begin{array}{l}\text { preço no mercado de } \\
\text { Agbogbloshie } \\
\text { (dólares } / \mathrm{kg})\end{array}$ & $\begin{array}{l}\text { preço no mercado } \\
\text { internacional } \\
\text { (dólares } / \mathrm{kg})\end{array}$ \\
\hline cobre & 3,91 & 6,11 \\
\hline brass & 3,13 & 5,78 \\
\hline zinco & 0,93 & 2,33 \\
\hline alumínio & 0,78 & 1,80 \\
\hline aço & 0,78 & 0,67 \\
\hline ferro & 0,21 & 0,30 \\
\hline
\end{tabular}

Fonte: Elaboração do autor (2017) com base em Oteng-Ababio (2012).

É fundamental apresentar aqui o potencial de recuperação de metais a partir do e-waste. Para se ter dimensão disso, por exemplo, a composição dos telefones celulares inclui cerca de $250 \mathrm{mg}$ de prata, $24 \mathrm{mg}$ de ouro, $9 \mathrm{mg}$ de paládio e $9 \mathrm{mg}$ de cobre, e sua bateria tem $3,8 \mathrm{~g}$ de cobalto. Já os computadores (desktop e laptop) contêm $1.000 \mathrm{mg}$ de prata, $220 \mathrm{mg}$ de ouro, $80 \mathrm{mg}$ de paládio e $500 \mathrm{~g}$ de cobre, e as baterias de laptop contêm $65 \mathrm{~g}$ de cobalto. Tomadas isoladamente, essas quantidades podem parecer insignificantes, mas, no contexto de produção e consumo mundial, tornam-se expressivas; haja vista que, em 2011, por exem- 
plo, foram produzidos 1,2 bilhão de telefones celulares e 255 milhões de computadores, e podem-se estimar as extraordinárias possibilidades de obtenção de lucro (United Nations Environment Programme, 2009).

Centrado numa força de trabalho mal remunerada que opera precária e informalmente, a recommodização da economia é um processo que expõe mais uma forma de expansão e inserção desigual dos países do sul no sistema capitalista. Agbogbloshie é a manifestação concreta desse processo.

A menos de um quilômetro do centro de Accra, Agbogbloshie é um bairro com cerca de 16 $\mathrm{km}^{2}$, onde vivem aproximadamente 80 mil pessoas, sendo a maior parte delas migrantes da porção norte do país ou imigrantes do Togo, de Burkina Faso e da Costa do Marfim. Abossey-Okai Road é a rua que leva até o local; é pavimentada e muito movimentada, como a maior parte das ruas da capital ganense. Há nela um fluxo contínuo de automóveis e vans (os tro-tros), que suprem a demanda do transporte coletivo. As calçadas são tomadas por vendedores, sejam eles ambulantes ou estabelecidos em barracas. Diferentes produtos são vendidos: alimentos como inhame, tomate, cebola, abacaxi, banana, biscoitos, água e refrigerantes; vestuário, em especial camisetas e calças jeans, e uma miríade de bens eletroeletrônicos que, em sua maior parte, são usados.

No bairro existe uma área destinada ao Mercado de Agbogbloshie - denominado oficialmente Makola Market II ${ }^{7}$ e outra área onde se distribuem moradias, oficinas de serviços diversos e o depósito de lixo. Só se pode circular nesse espaço com a autorização prévia de um grupo de homens postados na entrada principal do bairro: eles passam o dia sentados conversando entre si ou em seus respectivos aparelhos de telefone celular, sob um guarda-sol, usando óculos escuros e vestidos com camisetas de times de futebol europeu. A visita é possível desde que acompanhada por um deles e mediante o pagamento de 20 cedis (o equivalente a 5 dólares).

Existem dois tipos de lixo despejados em Agbogbloshie: o convencional e o eletroeletrônico. Muitas vezes misturados, eles se acumulam em montanhas de até dois metros de altura, presentes em diferentes pontos da paisagem (Figura 1). Pode-se observar que muitos trabalhadores - em sua maioria homens jovens entre 15 e 25 anos - desempenham ali diferentes atividades: alguns ficam sentados em roda conversando, enquanto desmantelam computadores, aparelhos televisores e outros objetos, na busca de recursos minerais; outros chegam em caminhões e despejam $e$-waste; e existem ainda aqueles que trabalham dentro de oficinas consertando e revendendo produtos eletrônicos.

Caminha-se dentro desse espaço por uma via paralela ao rio Odaw que, por sua vez, encontra-se poluído e com o fluxo obstruído pela presença de dejetos de diversos tipos: sacos plásticos, pedaços de computadores e geladeiras, pneus etc. Esse rio despeja suas águas na Lagoa Korle, que, outrora, foi importante fonte de peixes para a alimentação da população local. $\bigcirc$ desaparecimento de muitas espécies animais e vegetais desses corpos hídricos pode ser explicado pelas altas concentrações de chumbo, cobre e zinco, decorrentes das atividades econômicas em torno do e-waste (Huang et. al., 2014). É notória a presença de homens queimando produtos eletrônicos na beira do rio (Figura 2).

7 No mercado de Agbogbloshie, vendem-se essencialmente tomates e inhame, mas também frutas (abacaxi, manga e banana) e pimenta vermelha. $\bigcirc$ papel de comerciante cabe exclusivamente às mulheres que, sentadas no chão com suas bacias ou em cadeiras em sua barraca, vende seus produtos silenciosamente, sem apelos diretos aos consumidores, muito diferente do que fazem os comerciantes ambulantes nas ruas da cidade. 
Figura 1 - Acúmulo de lixo eletroeletrônico no bairro de Agbogbloshie (Accra, Gana) - 2016

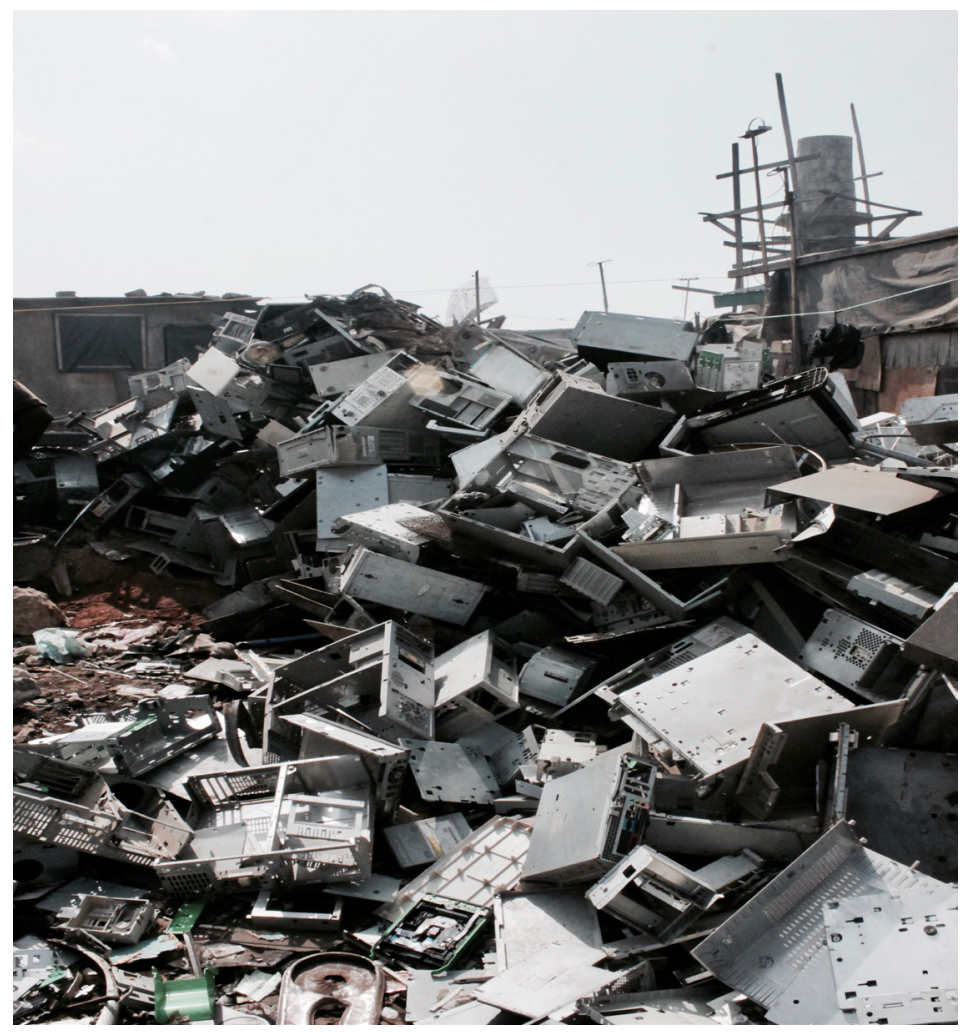

Fonte: Foto do autor (2017).

Figura 2 - Trabalhadores queimando lixo eletroeletrônico à beira de rio no bairro de Agbogbloshie (Accra, Gana) - 2016

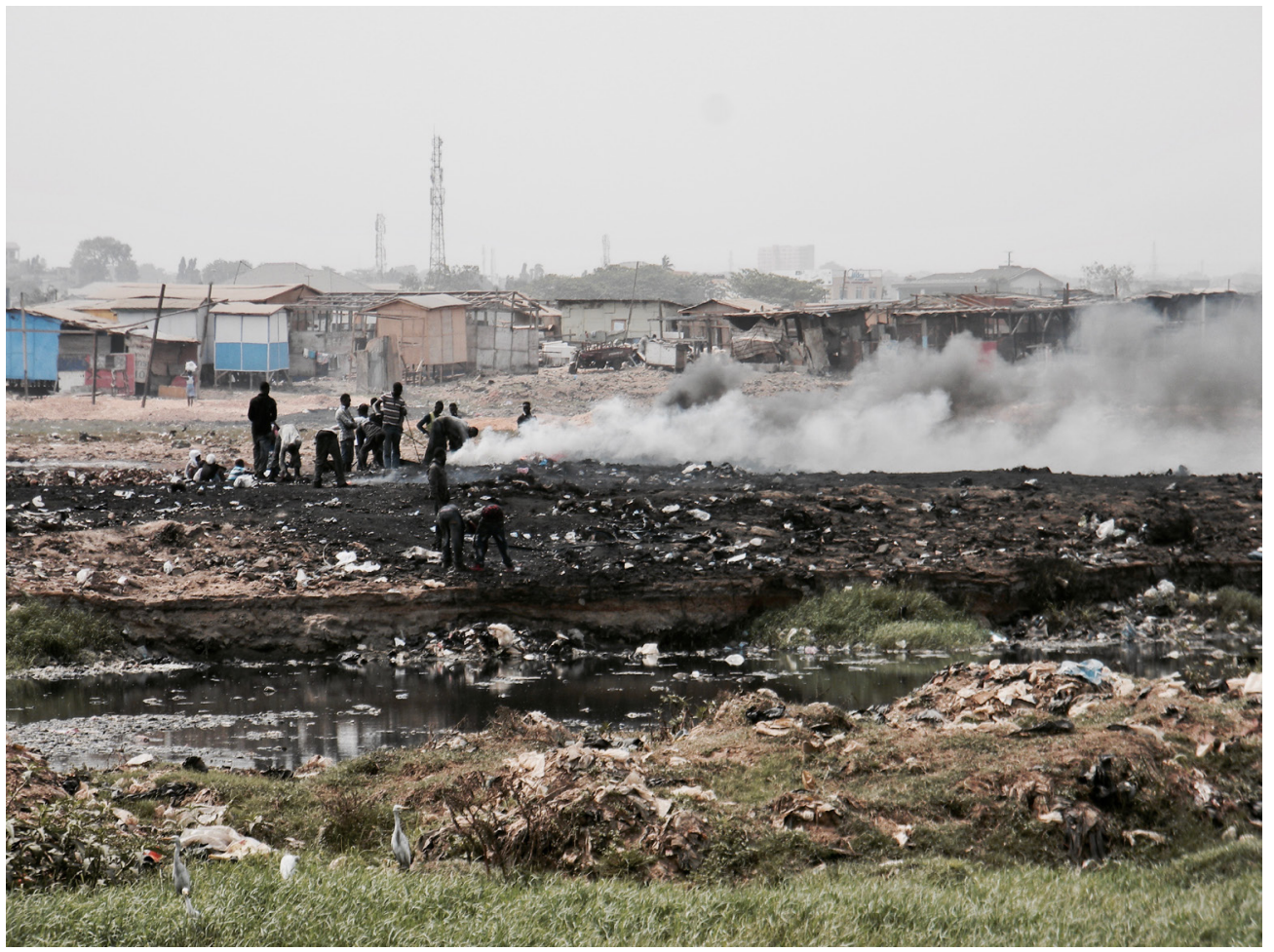

Fonte: Foto do autor (2017). 
As moradias do bairro são extremamente precárias, sendo, quase sempre, construídas com pedaços de madeira. A grande maioria tem antena parabólica e acesso a energia elétrica, mas não dispõe de saneamento básico, de modo que os dejetos humanos são jogados no rio Odaw. A presença de muitas mesquitas permite inferir uma concentração expressiva de população islamizada no bairro, o que é perfeitamente concebível, dado que cerca de $70 \%$ dos moradores de Agbogbloshie são oriundos das regiões ao norte do país, onde predomina o islamismo.

Acredita-se que as atividades de reciclagem e processamento de lixo eletroeletrônico - e a subsequente exportação da sucata e dos recursos minerais dele extraídos - perfaçam, em média, US\$ 52 bilhões por ano no mundo (Baldé et al., 2015). Em Gana, estima-se que, anualmente, a mineração urbana alcance US\$260 milhões (Oteng-Ababio; Amankwaa; Chama, 2014).

Tais atividades viabilizam o processo de recommodização da economia que, na formação socioespacial ganense, mobiliza um contingente significativo da força de trabalho, que opera, na maior parte dos casos, e condições precárias. Estima-se que haja seis mil pessoas envolvidas em atividades diretamente relacionadas ao lixo eletroeletrônico - importação, coleta, reciclagem, reparo, intermediação, exportação -, nas mais de 400 empresas, na maioria dos casos informais, existentes em Accra (Grant, 2016; Grant; Oteng-Ababio, 2012).

$\bigcirc$ lixo eletroeletrônico - especialmente no caso de computadores - é trazido por empresas de importação ganenses, geralmente organizadas em estrutura familiar, que atuam na escala internacional. Do mesmo modo, existem empresas de capital togolês, liberiano e nigeriano nessa atividade que, muitas vezes, também envolve a importação de automóveis usados (Chalfin, 2010; Burrell, 2012; Amankwaa, 2013). Localizadas essencialmente em Accra, é comum que essas empresas também tenham representantes em importantes cidades portuárias européias como Antuérpia (Bélgica), Hamburgo (Alemanha) e Roterdã (Holanda).

Inicialmente, as remessas que chegam ao porto de Tema são divididas em dois grupos:

1. equipamentos eletroeletrônicos com potencial para reutilização dentro da funcionalidade original e que serão vendidos nos mercados locais como produtos de segunda mão (cerca de 30\%) e

2. equipamentos eletroeletrônicos sem potencial para reutilização dentro da funcionalidade original (e-waste) (cerca de 70\%).

As importações do primeiro grupo são direcionadas para pequenas oficinas de reparo, localizadas em Accra ou em Tema, cidade portuária conurbada à capital. Lá, os objetos são testados, consertados e limpos, passando à comercialização em pequenas lojas ou mercados de rua espalhados por todo o território nacional. Já as importações do segundo grupo são levadas por coletores até o distrito de Agbogbloshie.

Encontrados pelas ruas da capital, os coletores - localmente conhecidos como kaya bola - são homens jovens que geralmente trabalham sozinhos ou em dupla, circulando pelo espaço urbano em busca de eletrônicos descartados. Eles frequentam não apenas a zona portuária, mas também áreas residenciais, oficinas mecânicas, centros comerciais e de negócios. A coleta do e-waste é feita com o auxílio de carros de mão e caminhões que, na maioria das vezes, são alugados diariamente com intermediários. Sempre portando algumas ferramentas - como chave de fenda, chave inglesa e martelo -, os coletores realizam um desmantelamento parcial 
do e-waste conforme os encontram. A jornada diária é longa, indo para além de 10 horas. Os objetos coletados são levados para Agbogbloshie, onde são vendidos aos intermediários. Em média, os coletores obtêm 15 cedis por dia (o equivalente a 3,9 dólares) (Amankwaa, 2013). Os intermediários, por sua vez, são aqueles que vendem os objetos trazidos pelos coletores aos recicladores e aos reparadores locais. $\bigcirc$ primeiro grupo trabalha ao ar livre ou nas pequenas oficinas do bairro. Suas atividades incluem o desmantelamento manual dos eletrônicos e a extração de recursos minerais valiosos de dentro dos mesmos.

No entanto, a falta de equipamento adequado permite apenas um processo parcial de reciclagem mineral. Ganhando em média 30 cedis por dia (o equivalente a 7,8 dólares), os recicladores muitas vezes adotam técnicas precárias e nocivas à saúde e ao ambiente, como a queima de fios ao ar livre para isolar o minério de cobre da borracha e do plástico. Nesse caso, os trabalhadores alimentam a combustão do fogo com pneus de automóveis sem usar nenhum tipo de proteção (Amankwaa, 2013).

A queima de e-waste em Agbogbloshie libera metais pesados que contaminam o ar local, o solo e os corpos hídricos. Esse processo também afeta a saúde respiratória dos trabalhadores do bairro, além de contaminar alimentos - em especial frutas, legumes e carnes - comercializados em mercados próximos (Basel Convention Secretariat, 2011; Huang et. al., 2014). Alguns levantamentos sanitários demonstraram a presença de uma elevada concentração de chumbo no solo - no valor de 18 mil ppm (partes por milhão), enquanto o padrão sugerido pela United States Environmental Protection Agency é de 400 ppm. Além disso, coletas de sangue e urina realizadas com os trabalhadores de Agbogbloshie revelam altas concentrações de bário, cobalto, cobre, ferro e zinco em seu organismo (Huang et. al., 2014).

Ali também se fazem consertos. Os reparadores são aqueles que tentam recuperar objetos para sua função original e reinseri-los no mercado local. Suas oficinas também ficam em Agbogbloshie, onde vendem os produtos recuperados. Além disso, as oficinas de conserto limpam os produtos para torná-los mais atraentes para os consumidores locais. Os objetos que eventualmente não podem ser recuperados passam pelo processo localmente dito "canibalismo": removem-se algumas de suas partes e se as armazenam para ajudar a recuperar outros eletrônicos. Em média, os reparadores ganham cerca de 25 cedis por dia (equivalente a 6,5 dólares) (Amankwaa, 2013).

Os intermediários, por sua vez, desempenham um papel central para as atividades de processamento do lixo eletroeletrônico na formação socioespacial ganense. Além de estabelecer as relações comerciais entre coletores, recicladores e reparadores, eles também fazem a conexão entre recicladores e sucateiros de Tema. É importante notar, contudo, que essas articulações são sempre financeiramente favoráveis aos intermediários. Amankwaa (2013, p. 563, tradução nossa) menciona que:

Descobriu-se que ajustou as escalas que medem sua vantagem (para pagar menos pelos materiais), o que explica a diferença de preços entre Agbogbloshie e Tema - uma área industrial onde ficam as grandes empresas de reciclagem de sucata. Após ponderação, mudanças de caixa de mãos e os bens entram no estoque e são eventualmente vendidos a sucateiros que, por sua vez, vendem a empresas em Tema. 
Os intermediários em Accra são, em sua maioria, ganeses, mas observa-se também a presença de togoleses, liberianos e nigerianos. Geralmente, eles obtêm 35 cedis por dia (o equivalente a 9 dólares) (Amankwaa, 2013).

A última etapa envolvida na mineração urbana é executada pelas empresas de processamento de sucata. Localizadas em Tema, essas fábricas compram das mãos dos intermediários sucatas e minerais já parcialmente processados pelos recicladores de Agbogbloshie. Diferente das atividades desempenhadas em Agbogbloshie, as empresas de sucata operam em situação de formalidade em grandes e bem estruturadas plantas fabris. É notória também a predominância do capital estrangeiro nesse tipo de atividade, em especial indiano (Succes Africa, Gravita, Commodities Processing e NN Est. Meta) e saudita (Goldline). Em função de suas condições de operação, essas empresas praticamente detêm o monopólio de exportação da sucata e dos minérios extraídos do lixo eletroeletrônico, em especial cobre e chumbo (Grant, 2016; Santos, K., 2017). Nos últimos anos, muitas delas têm procurado financiar diretamente a atividade dos coletores, para evitar a compra de sucata e de minérios via intermediários.

Nessas empresas, a mão de obra conta com melhores condições de trabalho, utilizando máquinas e instrumentos menos nocivos à saúde dos operários. Geralmente, são utilizadas técnicas de pirometalurgia e hidrometalurgia, que servem para isolar os recursos minerais que integram o e-waste. É comum certo tipo de especialização entre essas empresas, como a Gravita, que centra suas ações na reciclagem de sucatas com chumbo e sucatas com baterias, visando a exportação de lingotes de chumbo refundidos (com pureza de cerca de 97\%) e polipropileno (tipo de plástico reciclado) (Gravita Ghana Limited, [s.d.]).

Essas atividades econômicas tem aumentado as exportações ganenses de cobre, chumbo, sucata e minerais misturados desde 2004. De modo geral, essas exportações alcançam 31 países. Os maiores consumidores dessas exportações são nações que experimentam um acelerado processo de industrialização, como a China - principal importadora - e a Índia. Outros países que são compradores dessas recommodities são Japão, Austrália, Alemanha, Reino Unido, Holanda e Espanha (Santos, K., 2017).

Os recursos minerais extraídos do e-waste são exportados pelo porto de Tema e, quando chegam a seu destino, são usados como matéria-prima nos mais diferentes tipos de indústria. A sucata exportada, por sua vez, é processada por companhias de reciclagem ainda mais capitalizadas, capazes de desagregá-la mais eficientemente (Grant; Oteng-Ababio, 2012).

\section{Considerações finais}

Ouro para fora, lixo para dentro é a formulação sintética para a interpretação apresentada aqui sobre as formas de inserção de Gana na divisão internacional do trabalho contemporânea. Por mais que a exportação de commodities (em especial, de ouro) e a importação de bens industrializados ainda sejam características econômicas estruturais do país, novas dinâmicas

ganharam vigor no começo do século XXI e precisam passar a compor o quadro de análise de geógrafos e economistas.

Além da já tradicional importação de bens industrializados, Gana tornou-se também importadora de bens eletroeletrônicos de segunda mão que, chegando ao país em estado de deterioração parcial ou total, integram um volumoso (e ilegal) fluxo internacional de lixo. Acu- 
mulados em bairros como Agbogbloshie, na capital Accra, verdadeiras montanhas de produtos descartados por consumidores de países do norte induzem um conjunto de atividades econômicas que são responsáveis pela recommodização da economia.

A extração de recursos minerais de dentro do e-waste - por meio de técnicas precárias - e sua comercialização no mercado internacional dão origem às recommodities (os recursos em si) e à recommodização da economia, o processo de obtenção de valor a partir de lixo eletroeletrônico.

Este artigo procura não só contribuir com a interpretação do papel de Gana na economia internacional contemporânea, mas também destacar a importância de se estudarem as atividades econômicas que derivam do lixo, uma vez em que elas também geram valor e movimentam fluxos de mercadorias dentro da divisão internacional do trabalho.

\section{Referências}

AMANKWAA, E. Livelihoods in risk: exploring health and environmental implications of e-waste recycling as a livelihood strategy in Ghana. The Journal of Modern African Studies, v. 51, n. 4, p. 551-575, 2013.

ANIN, T. E. Gold in Ghana. Accra/London: Selwyin, 1989.

BAIR, J. Frontiers of Commodity Chains Research. Palo Alto: Stanford University Press, 2009.

BALDÉ, C. P.; WANG, F.; KUEHR, R.; HUISMAN, J. The global e-waste monitor 2014: quantity, flows and resources. Bonn: United Nations University/IAS-SCYCLE, 2015.

BASEL CONVENTION SECRETARIAT. Where are WEee in Africa? Findings From the Basel Convention e-waste Africa Programme, 2011. Disponível em: http://www. basel.int/Portals/4/Basel\%20Convention/docs/pub/WhereAreWeelnAfrica_ExecSummary_en.pdf. Acesso em: 27 ago. 2015.

BOAHEN, A. Ghana: evolution and change in the nineteenth and twentieth centuries. London: Longman, 1975.

BURRELL, J. Invisible users: youth in the internet cafés of urban Ghana. Cambridge: MIT Press, 2012.

CHALFIN, B. Neoliberal frontiers: an ethnography of sovereignty in West Africa. Chicago: University of Chicago Press, 2010.

DAVIDSON, B. A history of West Africa: 1000-1800. London: Longman, 1985.

GEERTZ, C. Peddlers and princes. Chicago: University of Chicago Press, 1963.

GEREFFI, G.; KORZENIEWICZ, M. Commodity chains and Global Capitalism. Westport: Praeger, 1994.

GHANA STATISTICAL SERVICE. 2015. Disponível em: http://www.statsghana.gov.gh. Acesso em: 10 jan. 2015. 
GRANT, R. The "Urban Mine" in Accra, Ghana. In: MAUCH, C. (Ed.). Out of Sight, Out of Mind: The Politics and Culture of Waste. RCC Perspectives - Transformations in Environment and Society, n. 1, p. 21-29, 2016.

GRANT, R.; OTENG-ABABIO, M. Mapping the invisible and real "African" Economy: Urban E-waste Circuitry. Urban Geography, v. 33, n. 1, p. 1-21, 2012.

GRAVITA GHANA LIMITED. Disponível em: http://www.gravitaghana.com. Acesso em: 12 fev. 2016.

HOPKINS, T.; WALLERSTEIN, I. Commodity Chains in the World-Economy Prior to 1800. Review - Fernand Braudel Center, v. 10, n. 1, p. 157-170, 1986.

HUANG, J.; NKRUMAH, P. N.; ANIM, D. O.; MENSAH, E. E-waste disposal effects on the aquatic environment: Accra, Ghana. Reviews of Environmental Contamination and Toxicology, v. 229, p. 19-34, 2014.

HUTCHFUL, E. Ghana's adjustment experience: the paradox of reform. Oxford: James Currey, 2002.

LABBAN, M. Deterritorializing Extraction: Bioaccumulation and the Planetary Mine. Annals of the Association of American Geographers, v. 104, n. 3, p. 560-576, 2014.

LEPAWSKY, J.; MATHER, C. From beginnings and endings to boundaries and edges: rethinking circulation and exchange through electronic waste. Royal Geography Society, v. 43, n. 3, p. 242-249, 2011.

MAMIGONIAN, A. A geografia e a formação social como teoria e como método. In: SEMINÁRIO INTERNACIONAL O MUNDO DO CIDADÃO, UM CIDADÃO DO MUNDO, set. 1996, São Paulo: USP.

MOORE, S. Global Garbage: Waste, Trash Trading, and Local Garbage Politics. In: PEET, R.; ROBBINS, P.; WATTS, M. (Ed.). Global Political Ecology. London: Routledge, 2011. p. 133-144.

OBSERVATORY OF ECONOMIC COMPLEXITY. Disponível em: http://atlas.media.mit. edu/en/. Acesso em: 26 abr. 2017.

OTENG-ABABIO, M. When Necessity Begets Ingenuity: E-Waste Scavenging as a Livelihood Strategy in Accra, Ghana. African Studies Quarterly, v. 13, n. 1-2, p. 1-21, 2012.

OTENG-ABABIO, M.; AMANKWAA, E. F; CHAMA, M. A. The Local Contours of Scavenging for E-waste and Higher-Value Constituent Parts in Accra, Ghana. Habitat International, v. 43, p. 163-171, 2014.

PICKREN, G. Political ecologies of electronic waste: uncertainty and legitimacy in the governance of e-waste geographies. Environment and Planning A, v. 46, p. 26-45, 2014.

RIMMER, D. Staying poor: Ghana's political economy, 1950-1990. Oxford: Pergamon, 1992. 
ROTHCHILD, D. Ghana: the political economy of recovery. Boulder: Lynne Rienner Publisher Inc., 1991.

SANTOS, K. L. Pontas em circuito: as inserções de Gana na divisão internacional do trabalho contemporânea. Tese (Doutorado em Geografia Humana) - Faculdade de Filosofia, Letras e Ciências Humanas, Universidade de São Paulo, São Paulo, 2017

SANTOS, M. Por uma outra globalização: do pensamento único à consciência universal. Rio de Janeiro: Record, 2000.

SANTOS, M. Sociedade e espaço: a formação social como teoria e como método. Boletim Paulista de Geografia, São Paulo: AGB, n. 54, p. 35-59, 1977.

SCHLUTER, T. Geological Atlas of Africa. Nairobi: Unesco, 2006.

UNITED NATIONS ENVIRONMENT PROGRAMME. Waste Crime - Waste Risks Gaps in Meeting the Global Waste Challenge: a Rapid Response Assessment. 2015. Disponível em: http://www.unep.org/publications/. Acesso em: 25 ago. 2015.

UNITED NATIONS ENVIRONMENT PROGRAMME. Recycling from e-waste to resources. 2009. Disponível em: http://www.unep.org/pdf/Recycling_From_e-waste_to_resources.pdf/. Acesso em: 25 ago. 2015. 